\title{
Physiological parameters of hemostasis in weakened newborn piglets and calves with gamavit injection
}

\author{
Elena V. Krapivina ${ }^{1 *}$ and Andrei L. Kryazhev ${ }^{2}$ \\ ${ }^{1}$ Bryansk State Agricultural University, Kokino village, Vygonichsky district, Bryansk region, 243365, Russia \\ ${ }^{2}$ Vologda State Dairy Farming Academy named after N.V. Vereshchagin, Vologda, 160555, Russia
}

\begin{abstract}
The deployment of the first stages of ontogenesis in all types of productive animals is determined by the change in hemostatic and rheological mechanisms. The status of these parameters strongly influences the deployment of heredity of an organism of any animal. The normal operation of the hemostasis during the neonatal strongly determines the rheological properties of blood, and therefore metabolism in the organs of young animals. Phase of neonatal calves and piglets is a serious stage of their development. Therein have the characteristic of hemostatic processes. The authors determined that during the first or second day of life in physically impaired calves and piglets develop physiologically unfavorable changes in haemostatic parameters, platelets, blood vessels and blood clotting. Emerging changes adversely affect the operation of their bodies and lead to total exclusion. The use of the drug gamavit enhances the weakened condition of newborn calves and piglets functionally acceptable reduce the activity of platelets and clotting of blood in a functionally justified the growth of the hemostatic capabilities of the vessels. It can be argued that injections of gamavit negate the existing dysfunction in hemostasis in physically weakened calves and piglets during the neonatal phase, increasing their adaptation and stimulating further growth and development of animals.
\end{abstract}

\section{Introduction}

Ontogenesis is always associated with a clear work of organs [1, 2]. Here the functioning of the nervous system [3] and the blood system [4, 5] is of great importance. Now researchers give special attention in various animal studies [6-8]. The debut of ontogenesis and the initial state of adaptation in calves and piglets is especially important and are associated with the success of hemocirculation [9]. Blood counts are largely determined by the hemostatic characteristics of platelets, blood vessels, and coagulation [10, 11].

It is clear that the activity of platelets, vascular hemostasis and hemocoagulation affects microcirculation in young animals [12]. The deterioration of hemostasis processes adversely affects the development of adaptive processes and inhibits the growth of calves and piglets [13].

A very vulnerable young growth that was born weakened [14]. It is possible to eliminate asthenia using various biologically active substances, which sometimes eliminate dysfunctions in the body [15]. A commonly used stimulant is gamavit.

However, his ability to influence hemostasis is unclear. For this reason, the following goal was set: to find out changes in hemostatic activity in weakened newborn calves and piglets treated with gamavit.

\section{Materials and methods}

This work was carried out in strict accordance with ethical standards defined by the European Convention for the Protection of Vertebrate Animals, which are used for experiments (adopted in Strasbourg on March 18, 1986 and confirmed in Strasbourg on June 15, 2006).

Physiologically mature, physically weakened newborn calves and piglets were taken to work. They were obtained from sows by the first farrow and from first-calf cows, which had a body mass below the norm during insemination.

Physically weakened newborn calves with 48 heads were under observation, which were examined twice: on the 1 st and 5th day of life. Also 39 weakened newborn piglets, which were examined on the 1 st and 5 th day of life.

All these animals received injections of gamavit at a dose of $0.03 \mathrm{ml} / \mathrm{kg}$ immediately after the first examination once a day, in the morning for 5 days. As a control, the arithmetic mean values were used for 42 healthy newborn calves and 35 newborn piglets, which were examined three times during the neonatal phase.

Platelet aggregation (AP) time was determined by a micromethod with ADP $\left(0.5 \times 10^{-4} \mathrm{M}\right)$ and with collagen (1: 2 dilution from the main suspension) [5].

The antiaggregatory capabilities of the vessels were determined during the assessment of antibodies in

*Corresponding author: ilmedv1@yandex.ru 
plasma taken without and against the background of temporary venous occlusion with the calculation of the index of anti-aggregatory activity of the vessel wall.

This was done by dividing the time of AP in plasma taken under conditions of temporary venous occlusion by the duration of AP in plasma taken without it [5]. Vascular control over blood coagulation was determined by the activity of antithrombin III in intact and in plasma obtained from blood after temporary venous occlusion [5].

The index of anticoagulation activity of the vascular wall was calculated during the division of the activity of antithrombin III in plasma after venous occlusion by its activity in intact plasma. The state of vascular control over the fibrinolysis process was evaluated by accelerating euglobulin lysis in intact plasma and in plasma taken under conditions of temporary venous occlusion [5].

The index of fibrinolytic activity of the vascular wall was calculated by dividing the duration of euglobulin lysis in intact plasma by the duration of euglobulin lysis in plasma taken with the application of a cuff on the vessel.

The functional activity of coagulation blood was evaluated by the value of prothrombin time, blood coagulation time in the activated partial thromboplastin time test, and by the duration of coagulation in the thrombin time test using traditional methods [5]. The obtained results were processed using Student's criterion (td).

\section{Results}

While taking the study in the blood weakened piglets and calves had normal platelet count. They also time at with collagen was accelerated to $21.3 \pm 0.19 \mathrm{~s}$, yielding values of the control $46.5 \%$. Accelerated were calves and at with $\operatorname{ADP}(51.5 \%)$. The time of occurrence of at in piglets with collagen was also accelerated by $52.4 \%$. With ADP at they occurred earlier than in controls by $43.7 \%$.

The outcome in debilitated calves showed a reduction in the vascular effects at: with ADF the value of the index antiaggregatory activity of the vascular wall inferior to the control of $18.3 \%$, collagen was less control by $21.2 \%$. The outcome in debilitated pigs also reduced the impact of vessels on the at: of ADF with the level of the index antiaggregatory activity of the vascular wall were reduced control by $12.2 \%$, with collagen the level inferior to the control values by $17.9 \%$.

At the first examination in debilitated calves decreased synthesis in the blood vessels of antithrombin III. Its level in their blood was reduced by $15.1 \%$, while the index of anticoagulation activity of blood vessels inferior to the control of $14.6 \%$. These calves source found increase time euglobulin lysis by $26.8 \%$, while the reduction of the index of fibrinolytic activity of blood vessels by $13.6 \%$. In immunocompromised piglets source was found to decrease in antithrombin III activity and a decrease in the index of anticoagulation activity of blood vessels (13.0\%).
At the same time euglobulin lysis was increased by $24.2 \%$, while the index of the fibrinolytic activity of the vascular wall inferior to the control by $13.0 \%$.

Coagulation development time in basic coagulation tests in experimental calves was accelerated: activated partial thromboplastin time by $27.2 \%$, prothrombin time by $26.9 \%$ and thrombin time by $14.8 \%$. A similar acceleration of hemocoagulation in these tests was found in experimental piglets: activated partial thromboplastin time by $22.5 \%$, prothrombin time by $23.1 \%$ and thrombin time by $11.8 \%$.

Due to the appointment of gamavit in the blood of experimental piglets and calves, the optimal platelet concentration was maintained. Moreover, in these calves, AP in response to collagen increased to $30.1 \pm 0.22 \mathrm{~s}$, from ADP to $38.6 \pm 0.16 \mathrm{~s}$, reaching a control level in both cases. Experimental piglets also achieved a level of control of the values of antibodies with collagen and ADP.

The injection of gamavit caused weakened calves to normalize vascular control over antibodies. This was evidenced by the increase in their index of antiaggregation activity of the vessel wall with both inductors. In experimental piglets that were injected with gamavit, normalization of the values of the indices of anti-aggregation activity of the vascular wall was achieved due to their increase with ADP by $10.1 \%$, with collagen by $13.4 \%$.

In experimental calves that received gamavit, an increase in the synthesis of antithrombin III by the vessels was found, as indicated by an increase in it in the blood by $10.5 \%$ and an increase in the index of anticoagulation activity of the vascular wall to the level of $1.30 \pm 0.05$. They also noted stimulation in the vessels of the synthesis of tissue activator of palazminogen. This was evidenced by a decrease in euglobulin lysis time by $19.7 \%$ and an increase in the index of vascular fibrinolytic activity by $11.2 \%$.

As a result of the use of gamavit, weakened piglets achieved an increase in blood activity of antithrombin III by $12.4 \%$ with an increase in the index of anticoagulation activity of the vessel wall by $12.2 \%$. In those receiving correction courses, the vascular stimulation of fibrinolysis increased to normal. This was evidenced by a decrease in the time of euglobulin lysis by $19.9 \%$ and an increase in the index of vascular fibrinolytic activity by $11.4 \%$.

Against the background of the correction performed in young experimental groups, the coagulation time in the main coagulation tests was reduced to normal. Activated partial thromboplastin time increased in calves by $20.9 \%$, prothrombin time increased by $21.9 \%$ and thrombin time was inhibited by $12.3 \%$.

A similar dynamics of coagulation duration in the main coagulation tests occurred in experimental piglets that were given gamavit. Their clotting time was optimized due to an increase in the level of activated partial thromboplastin time by $21.2 \%$, prothrombin time by $18.9 \%$, and thrombin time by $8.7 \%$. 


\section{Discussion}

A biologically significant blood system is rightly considered a hemostatic system [16]. Her normal work at any age largely determines the rheological properties of blood that supports homeostasis [17]. The weakening of the tension of platelets, vascular and coagulation hemostasis in weakened calves and piglets greatly facilitates their adaptation to any environmental conditions.

The performed assessment of changes in platelet aggregation gave reason to say that the use of gamavit in weakened young leads to a decrease in excessive platelet sensitivity to external influences. This led in calves and piglets of the experimental groups to inhibition of antibodies to normal [18].

As a result of the changes found in experimental calves and piglets treated with gamavit, there was a decrease in the level of sensitivity of platelets to aggregation stimulants. This caused young animals of both types of animals to reach its level typical for control. Obviously, they were based on the normalization of the number of fibrinogen receptors, the activity of phospholipases $\mathrm{A}_{2}$ and $\mathrm{C}$, and the severity of thromboxane formation in platelets [19], which were excessive in experimental animals initially.

The increase in vascular anti-aggregation capabilities obtained in the case of gamavit injections in young animals of both animal species is explained by the activation of synthesis of prostacyclin and nitric oxide in their vessels, which inhibit platelet function, which ensured optimal microcirculation in organs [20].

The level of its anticoagulant and fibrinolytic properties was of great importance in ensuring the atrombogenic parameters of blood vessels in experimental calves and piglets. This is caused by activation of the synthesis of antithrombin III in the vessel walls [21] and the intensification of the generation of plasminogen activators in them. The injections of gamavit improved the function of hemostasis in experimental young animals of both species.

We see that the achievement of a physiological norm in their organism is associated with the normalization of anabolism, depression of plasma lipid peroxidation, leveling of intoxication phenomena and infectious processes. Serious factors in optimizing hemostasis are the normalization of metabolism in the blood, vessel walls, and liver [22].

Weakening to the level of norm coagulation of the properties of plasma of young animals of both species of productive animals treated with gamavit, has been reduced to a normal level of activity of individual coagulation factors [5], implementing the two mechanisms of blood coagulation [7]. This proves the obtained deceleration at young of time values in common coagulation tests: activated partial thromboplastin time, prothrombin time and thrombin time [9].

Table 1. State of hemostasis in physically impaired newborn calves and piglets against the background of gamavit

\begin{tabular}{|c|c|c|c|c|c|c|}
\hline \multirow[t]{2}{*}{ Indicators hemostasis } & \multicolumn{3}{|c|}{ Newborn calves, $\mathrm{M} \pm \mathrm{m}$} & \multicolumn{3}{|c|}{ Newborn piglets, $\mathrm{M} \pm \mathrm{m}$} \\
\hline & $\begin{array}{c}\text { at the beginning } \\
\text { of observation, } \\
n=48\end{array}$ & $\begin{array}{c}\text { at the end of the } \\
\text { observation, } \\
n=48\end{array}$ & $\begin{array}{l}\text { control } \\
\text { group, } \\
\mathrm{n}=42\end{array}$ & $\begin{array}{c}\text { at the beginning } \\
\text { of observation, } \\
n=39\end{array}$ & $\begin{array}{c}\text { at the end of the } \\
\text { observation, } \\
n=39\end{array}$ & $\begin{array}{l}\text { control } \\
\text { group, } \\
\mathrm{n}=35\end{array}$ \\
\hline $\begin{array}{c}\text { Platelet aggregation time } \\
\text { with ADP, s }\end{array}$ & $26.8 \pm 0.12$ & $\begin{array}{c}38.6 \pm 0.16 \\
\mathrm{p}_{1}<0.01\end{array}$ & $\begin{array}{c}40.6 \pm 0.10 \\
\mathrm{p}<0.01\end{array}$ & $27.2 \pm 0.14$ & $\begin{array}{c}37.6 \pm 0.10 \\
\mathrm{p}_{1}<0.01\end{array}$ & $\begin{array}{c}39.1 \pm 0.16 \\
\mathrm{p}<0.01\end{array}$ \\
\hline $\begin{array}{l}\text { Platelet aggregation time } \\
\text { with collagen, s }\end{array}$ & $21.3 \pm 0.19$ & $\begin{array}{c}30.1 \pm 0.22 \\
\mathrm{p}_{1}<0.01\end{array}$ & $\begin{array}{c}31.2 \pm 0.14 \\
\mathrm{p}<0.01\end{array}$ & $20.2 \pm 0.24$ & $\begin{array}{c}29.6 \pm 0.17 \\
\mathrm{p}_{1}<0.01\end{array}$ & $\begin{array}{c}30.8 \pm 0.09 \\
\mathrm{p}<0.01\end{array}$ \\
\hline $\begin{array}{l}\text { The value of the index of } \\
\text { antiplatelet activity of } \\
\text { the vascular wall with } \\
\text { ADP }\end{array}$ & $1.42 \pm 0.17$ & $\begin{array}{c}1.60 \pm 0.10 \\
\mathrm{p}_{1}<0.01\end{array}$ & $\begin{array}{c}1.68 \pm 0.13 \\
\mathrm{p}<0.01\end{array}$ & $1.48 \pm 0.19$ & $\begin{array}{c}1.63 \pm 0.16 \\
\mathrm{p}_{1}<0.01\end{array}$ & $\begin{array}{c}1.66 \pm 0.17 \\
p<0.01\end{array}$ \\
\hline $\begin{array}{l}\text { The value of the index of } \\
\text { antiaggregatory activity } \\
\text { of the vascular wall with } \\
\text { collagen }\end{array}$ & $1.32 \pm 0.07$ & $\begin{array}{c}1.56 \pm 0.09 \\
\mathrm{p}_{1}<0.01\end{array}$ & $\begin{array}{c}1.60 \pm 0.08 \\
p<0.01\end{array}$ & $1.34 \pm 0.11$ & $\begin{array}{c}1.52 \pm 0.08 \\
\mathrm{p}_{1}<0.01\end{array}$ & $\begin{array}{c}1.58 \pm 0.10 \\
\mathrm{p}<0.01\end{array}$ \\
\hline $\begin{array}{l}\text { Activity antithrombin III, } \\
\%\end{array}$ & $86.7 \pm 0.14$ & $\begin{array}{l}95.8 \pm 0.18 \\
\mathrm{p}_{1}<0.01 \\
\end{array}$ & $\begin{array}{c}99.8 \pm 0.17 \\
\mathrm{p}<0.01\end{array}$ & $85.6 \pm 0.10$ & $\begin{array}{c}96.2 \pm 0.14 \\
\mathrm{p}_{1}<0.01\end{array}$ & $\begin{array}{c}98.6 \pm 0.21 \\
\mathrm{p}<0.01\end{array}$ \\
\hline $\begin{array}{c}\text { Value index of } \\
\text { anticoagulation activity } \\
\text { of the vascular wall }\end{array}$ & $1.16 \pm 0.06$ & $\begin{array}{c}1.30 \pm 0.05 \\
\mathrm{p}_{1}<0.01\end{array}$ & $\begin{array}{c}1.33 \pm 0.07 \\
\mathrm{p}<0.01\end{array}$ & $1.15 \pm 0.09$ & $\begin{array}{c}1.29 \pm 0.04 \\
\mathrm{p}_{1}<0.01\end{array}$ & $\begin{array}{c}1.30 \pm 0.05 \\
\mathrm{p}<0.01\end{array}$ \\
\hline $\begin{array}{c}\text { Time spontaneous } \\
\text { euglobulin lysis time, min }\end{array}$ & $236.0 \pm 0.42$ & $\begin{array}{c}197.2 \pm 0.37 \\
\mathrm{p}_{1}<0.01\end{array}$ & $\begin{array}{c}186.1 \pm 0.41 \\
\mathrm{p}<0.01\end{array}$ & $227.5 \pm 0.54$ & $\begin{aligned} 189.7 \pm 0.32 \\
\mathrm{p}_{1}<0.01\end{aligned}$ & $\begin{array}{c}183.1 \pm 0.32 \\
\mathrm{p}<0.01\end{array}$ \\
\hline $\begin{array}{l}\text { Value index of } \\
\text { fibrinolytic activity of } \\
\text { the vascular wall }\end{array}$ & $1.25 \pm 0.06$ & $\begin{array}{c}1.39 \pm 0.11 \\
\mathrm{p}_{1}<0.01\end{array}$ & $\begin{array}{c}1.42 \pm 0.16 \\
\mathrm{p}<0.01\end{array}$ & $1.23 \pm 0.09$ & $\begin{array}{c}1.37 \pm 0.07 \\
\mathrm{p}_{1}<0.01\end{array}$ & $\begin{array}{c}1.39 \pm 0.12 \\
\mathrm{p}<0.01\end{array}$ \\
\hline $\begin{array}{c}\text { Activated partial } \\
\text { thromboplastin time, } \mathrm{s}\end{array}$ & $31.6 \pm 0.16$ & $\begin{array}{c}38.2 \pm 0.21 \\
\mathrm{p}_{1}<0.01\end{array}$ & $\begin{array}{c}40.2 \pm 0.30 \\
\mathrm{p}<0.01\end{array}$ & $32.0 \pm 0.28$ & $\begin{array}{c}38.8 \pm 0.19 \\
\mathrm{p}_{1}<0.01\end{array}$ & $\begin{array}{c}39.2 \pm 0.24 \\
\mathrm{p}<0.01\end{array}$ \\
\hline Prothrombin time, $\mathrm{s}$ & $14.1 \pm 0.19$ & $\begin{array}{c}17.2 \pm 0.20 \\
\mathrm{p}_{1}<0.01\end{array}$ & $\begin{array}{c}17.9 \pm 0.18 \\
\mathrm{p}<0.01\end{array}$ & $14.3 \pm 0.15$ & $\begin{array}{c}17.0 \pm 0.24 \\
\mathrm{p}_{1}<0.01\end{array}$ & $\begin{array}{c}17.6 \pm 0.16 \\
\mathrm{p}<0.01\end{array}$ \\
\hline Thrombin time, $\mathrm{s}$ & $16.2 \pm 0.29$ & $\begin{array}{c}18.2 \pm 0.21 \\
\mathrm{p}_{1}<0.01\end{array}$ & $\begin{array}{c}18.6 \pm 0.20 \\
\mathrm{p}<0.01\end{array}$ & $16.1 \pm 0.31$ & $\begin{array}{c}17.5 \pm 0.18 \\
\mathrm{p}_{1}<0.01\end{array}$ & $\begin{array}{c}18.0 \pm 0.25 \\
\mathrm{p}<0.01\end{array}$ \\
\hline
\end{tabular}


Note: $\mathrm{p}$ - significance of differences in outcome and control, $\mathrm{p} 1$ - significance of differences in the dynamics of indicators during correction.

\section{Conclusion}

Identified in the course of the study the dynamics of platelet and vascular hemostasis of coagulation of blood in young productive animals in case of application of gamavit had physiological character. It is provided both in calves and piglets achieving their normal values. The resulting optimization of the functions of hemostasis in physically weakened calves and piglets as a result of application of gamavit proved the possibility of full normalization of hemocirculation and metabolism in muscles and in internal organs weakened calves.

\section{References}

1. E.S. Tkacheva, S.Yu. Zavalishina, Physiology of Platelet Hemostasis In Piglets During The Phase Of Newborns, Res. J. of Pharmaceut., Biolog. and Chemical Sci., 9(5), 1912-1918 (2018)

2. V.I. Maksimov, S.Yu. Zavalishina, A.V. Parakhnevich, E.N. Klimova, N.A. Garbart, A.A. Zabolotnaya, Yu.I. Kovalev, T.Yu. Nikiforova, E.I. Sizoreva, Physiological Dynamics of Microrheological Characteristics Of Erythrocytes In Piglets During The Phase Of Milk Nutrition, Res. J. of Pharmaceut., Biolog. and Chemical Sci., 9(5), 454-459 (2018)

3. T.I. Glagoleva, I.N. Medvedev, Physiological Features Of Anti-aggregational Control Of Blood Vessels Over The Shaped Elements Of Blood In Calves At The Onset Of Ontogenesis, Res. J. of Pharmaceut., Biolog. and Chemical Sci., 9(5), 440-447 (2018)

4. S.Yu. Zavalishina, Functional Properties Of Coagulation Hemostasis In Calves During The Phase Of Dairy-Vegetative Nutrition, Res. J. of Pharmaceut., Biolog. and Chemical Sci., 9(5), 784-790 (2018)

5. Z.S. Barkagan, A.P. Momot, Diagnosis and controlled therapy of hemostatic disorders (Moscow, 2008)

6. I.N. Medvedev, T.A. Kumova, Valsartan effects on platelet activity in patients with arterial hypertension and metabolic syndrome, Russ. J. of Cardiol., 3, 66-69 (2007)

7. L.V. Korepanova, O.S. Starostina, S.D. Batanov, Blood as an indicator of the interior characteristics of crossbred animals, Zootechny, 10, 26-28 (2015)

8. S.Yu. Zavalishina, Functioning Of Mechanisms Of Hemocoagulation Restriction In Calves At Change Of Methods Of Nutrition, Res. J. of Pharmaceut., Biolog. and Chemical Sci., 9(5), 800-806 (2018)

9. S.Yu. Zavalishina, Functioning Of Platelets In Milk And Vegetable Nutrition Calves, Res. J. of Pharmaceut., Biolog. and Chemical Sci., 9(5), 943-949 (2018)
10. G.S. Mal, N.V. Vorobyeva, A.V. Makhova, I.N. Medvedev, I.I. Fayzullina, Features Of Physical Rehabilitation After Myocardial Infarction, Res. J. of Pharmaceut., Biolog. and Chemical Sci., 9(6), 280-285 (2018)

11. I.N. Medvedev, T.A. Kumova, Angiotensin II receptor inhibitors: role and place in arterial hypertension and metabolic syndrome treatment, Russ. J. of Cardiol., 5, 97-99 (2007)

12. S.Yu. Zavalishina, Functional Activity Of Plasma Hemostasis In Neonatal Calves With Iron Deficiency, Who Received Ferroglucin And Glycopin, Res. J. of Pharmaceut., Biolog. and Chemical Sci., 9(5), 1186-1191 (2018)

13. S.Yu. Zavalishina, Functional Properties Of Anticoagulation And Fibrinolysis In Calves Of Plant Nutrition, Res. J. of Pharmaceut., Biolog. and Chemical Sci., 9(5), 1082-1087 (2018)

14. S.Yu. Zavalishina, Physiology of Vascular Hemostasis In Newborn Calves, Res. J. of Pharmaceut., Biolog. and Chemical Sci., 9(5), 1037-1044 (2018)

15. M.P. Kirilov, A new generation of biologically active substances in animal feeding, Feeding farm animals and fodder production, 3, 34-37 (2006)

16. S.Yu. Zavalishina, Functional Properties Of Hemocoagulation In Calves Of Dairy Nutrition, Res. J. of Pharmaceut., Biolog. and Chemical Sci., 9(5), 1016-1022 (2018)

17. S.Yu. Zavalishina, Deficiency Of Iron As A Cause Of Dysfunction In Calves And Piglets, Res. J. of Pharmaceut., Biolog. and Chemical Sci., 9(5), 978-983 (2018)

18. G.M. Bazhov, L.A. Bakhirev, G.A. Urban, Formation of immune function in pregnant and lactating sows when fed biologically active substances, Zootechny, 4, 24-25 (2012)

19. S.Yu. Zavalishina, Functional Antiaggregatory Properties Of Blood Vessels In Calves During Transition From Dairy To Plant Type Of Nutrition, Res. J. of Pharmaceut., Biolog. and Chemical Sci., 9(5), 1110-1116 (2018)

20. S.Yu. Zavalishina, Physiological Features of Vascular Hemostasis In Calves Of Dairy-Vegetative Food, Res. J. of Pharmaceut., Biolog. and Chemical Sci., 9(5), 1137-1143 (2018)

21. S.Yu. Zavalishina, Functional Features Of Platelets In Newborn Calves With Iron Deficiency, Res. J. of Pharmaceut., Biolog. and Chemical Sci., 9(5), 1153-1158 (2018)

22. I.N. Medvedev, O.V. Gamolina, Lisinopril effects on platelet activity in patients with arterial hypertension and impaired glucose tolerance, Russ. J. of Cardiol., 3, 45-48 (2008) 